\title{
A REFORMA SANITÁRIA E A PARTICIPAÇĀO DO ENFERMEIRO
}

\author{
Iara de Moraes Xavier* \\ Carmen L. L. Garcia** \\ Maria Aparecida de Luca Nascimento***
}

\begin{abstract}
RESUMO - Discute a Reforma Sanitária brasileira como um processo técnico e político abordando os aspectos sociais e administrativos. Apresenta opiniōes de enfermeiras que atuam nas Unidades Assistenciais do INAMPS situadas nas regiōes Norte, Nordeste, Centro-Oeste, Sul e Sudeste sobre conceituação, expectativas quanto à sua implantação, participação da enfermeira, entendimento do processo em função da população e o significado da Reforma Sanitária frente ao compromisso social da Enfermagem.
\end{abstract}

\begin{abstract}
It discuss the Brazilian Sanitary Reform as a technical and political process, aproaching the economic, social and administrative aspects. It presents opinions of nurses that act in Assistencial Units of INAMPS located in North, Northest, Midwest, South and southest Regions, about concept, expectations about its implantation, nurse's participation, understanding of the process according the population and the meaning of Sanitary Reform related to the social commitment of Nursing.
\end{abstract}

\section{INTRODUÇĀO}

Ao ressurgir uma nova época onde todas as expectativas vão ao encontro de questionamentos profissionais mais freqüentes, depara-se, vez por outra, com a inquietude própria do atual momento.

Seria diff́cil o consenso, no que diz respeito às expectativas profissional, política, técnico-científica. Evidentemente, o descompasso entre cada um desses componentes, acarreta um desnivelamento com sérias implicaçōes.

A mudança observada com relaçã̉o a objetivos políticos de saúde, não permitiu o seu acompanhamento nos diversos niveis dos profissionais dessa área, em especial, da enfermagem.

Muito se tem falado sobre as causas e conseqüências dessa desinformação, mas, o que se pode observar de imediato é que o enfermeiro, enquanto parte integrante de uma sociedade, atuando técnica e cientificamente, não responde à conclamação social e política desta mesma sociedade.

Sendo a Reforma Sanitária um movimento social que depende do comprometimento dos profissionais de saúde com a população e considerando que não há movimento social sem interação pessoal, é desejável que o enferineiro esteja seriamente empenhado na realização desta proposta.

O presente estudo versa sobre essa problemática, pretendendo enfocar toda a expectativa que a Reforma Sanitária gera no enfermeiro, enquanto um movimento social de base rumo à assistência integralizada para toda a população.

\section{REVISĀO DE LITERATURA}

A Reforma Sanitária, por ser um processo técnico e político, passa a ser analisado no contexto histórico das Políticas Econômica, Social e Administrativa do País.

O iń́cio desse movimento sanitário brasileiro se deu na década de 20 com a criação do primeiro órgão nacional responsável pela política de saúde, o Departamento Nacional de Saúde Pública dirigido por Carlos Chagas. Em 1930 organizou-se o Ministério de Educação e Saúde.

O perf́odo de 1960 a 1964 caracterizou-se pela inexistência de uma Política de Saúde. O que houve foram programas de âmbito internacional, integrando instituiçōes nacionais e internacionais - Ministério da Saúde, OMS e UNICEF.

Evento mais significativo, nessa época, foi a III Conferência Nacional de Saúde (1963) que recomendou o modelo de cobertura, partindo da Atenção Primária de Saúde até a Atenção Terciária, denunciou a tendência de especialização e o uso de equipamentos sofisticados que contriburam para a dependência estrangeira.

A partir de 1984, a área de saúde passou por um processo de centralização e privatização, compat1vel com a estrutura de poder instaurada no País.

"No caso especifico de Saúde Pública as suas deficiências se reduzem à ausência de planificação, à falta de capacidade gerencial e incrivelmente à pouca iniciativa particular. Isto é: os problemas seriam resolvidos pela privatização

\footnotetext{
* Enfermeira - Coordenadora de Administração de Atividades de Enfermagem do INAMPS. Mestrando em Ciências da Enfermagem da UNI-RIO. Professora Assistente do Departamento de Enfermagem Médico - Cirúrgica / UNI-RIO.

** Enfermeira - Professor Assistente do Departamento de Enfermagem de Saúde-Pública / UNI-RIO. Mestrando em Educação na UFF. *** Enfermeira da Coordenadoria de Administração de Atividades de Enfermagem do INAMPS - Professora Assistente do Departamento de Enfermagem Materno-Infantil / UNI-RIO. Mestre em Ciências da Enfermagem.
} 
dos serviços de saúde. As doenças capazes de atingir grandes porções da população brasileira continuavam dentro do campo de Saúde Pública, ficando o atendimento médido de cunho individual como responsabilidade do setor previdenciário. A medicalização da vida social foi imposta tanto na saúde pública, quanto na previdência social. O resultado dos planos e das decisões em Saúde Pública pode ser verificado através das despesas. A participação do Ministério da Saúde nas despesas totais feitas pelo governo federal caiu de $68 \%$ em 1965 para $57,9 \%$ em 1968, descendo ainda mais para $39,2 \%$ em 1971"'. (VIEIRA, 1978).

Em 1967, acompanhando a tendência de centralização observada nos órgãos federais, a assistência previdenciária foi uniformizada e unificada, fundindo todos os Institutos de Pensões em somente um, o Instituto Nacional de Previdência Social - INPS.

Em 1968, foi implantado o Plano Nacional de Saúde que não se concretizou, dando lugar a uma politica que favorecia a privatização do setor, enfatizando a hospitalização. Conseqüentemente, incrementando a indústria farmacêutica e a tecnologia sofisticada dos equipamentos médico-hospitalares.

A opção governamental por essa política de saúde, acentuou a concentração de renda, aumentou a dependência do Brasil aos países mais avançados que dominam essas tecnologias e provocando uma baixa na qualidade de vida da população brasileira.

"A política de saúde de 1968 favorecia a atenção no setor privado. O Plano Nacional de Saúde foi aplicado em três áreas experimentais (piloto), das quais só se tem análise dos resultados de duas áreas: Nova Friburgo e Goiânia. Os técnicos do Ministério da Saúde investigaram a implantação do Plano Nacional de Saúde, chegando à conclusão de que este era inviável, tendo em vista a inexistência de uma estrutura econômico-financeira que garantisse os recursos necessários à aplicação do plano a nível nacional". (MELLO 1982)

"O início da década de 70 até 74 é marcado por forte repressão política, no auge do Milagre Econômico. A tendência marcante na estrutura orçamentária do Estado Brasileiro é voltada para a centralização do poder político e econômico em função do capital e em detrimento, portanto, das despesas com o bem-estar social". (COSTA, 1987)

"Ante tal situação, a política de saúde, iniciativa do Estado, vai expresar também os interesses do capital, passando a privilegiar toda uma assistência curativa, onde a indústria farmacêutica e de equipamentos têm lugar especial". (GERMANO, 1984)

Todas essas citaçōes foram reforçadas quando em 1974 foi criado o Ministério da Previdência e Assistência Social, que se tornou, desde logo, o deten- tor do maior orçamento da República, inferior apenas ao orçamento geral da União.

Em setembro de 1977, foi implantado o Sistema Nacional de Previdência e Assistência Social - SINPAS -, através da Lei n. 6.439. Integrante do SINPAS, o Instituto Nacional de Assistência Médica da Previdência Social - INAMPS - assumiu a liderança da Assistência Médica Individual e Curativa.

A necessidade de disciplinar os serviços de saúde no país foi reconhecida pela Presidência da República em 1975, quando promulgou sob o n. 6.229, a lei em que o Congresso Nacional dispôs sobre a organização do Sistema Nacional de Saúde. Essa lei legitimou e institucionalizou a pluralidade no setor, ou seja: definiu em suas grandes linhas as responsabilidades das várias instituições, como a Previdência Social encarregada da assistência curativa, e o Ministério da Saúde, acolitado pelas Secretarias Estaduais e Municipais de Saúde responsáveis pelos cuidados preventivos de alcance coletivo.

A despeito desse evidente empenho em organizar e disciplinar a atuação dos órgãos do setor público no campo da proteção da saúde, ocorreu o agravamento das deformações de uma atividade que cada vez mais enfatiza a hospitalização, em detrimento das ações preventivas e da atenção primária tão necessárias à proteção da saúde.

No fim da década de 70, os movimentos sociais como a campanha pela anistia, em defesa da Amazônia, contra os contratos de risco e as pressões da classe trabalhista, como a greve dos metalúrgicos do. ABC-São Paulo e as greves dos profissionais de saúde, em todo o país, levaram o governo a propor políticas que contivessem esses movimentos, através de programas pseudamente sociais.

As Conferências Nacionais de Saúde, realizadas em 1975, 1977 e 1980, respectivamente, V, VI e VII, inclúram em seus discursos estratégias de extensão de cobertura das ações de saúde, principalmente nas regiōes carentes.

Vários foram os programas sugeridos para tentar revalorizar os cuidados primários na proteção da saúde como: o Plano Integração das Ações de Saúde e Saneamento (PIASS), o Plano de Localização de Unidades de Saúde (PLUS), o PREV-SAÚDE e muitos outros, menos ambiciosos em extensão territorial, mas igualmente em seus propósitos sociais.

Projetos e programas desse tipo enfaticamente recomendados na 7. Conferência Nacional de Saúde e na Última Reunião da Organização Mundial de Saúde, em Alma-Ata.

"Em seguida, surgiu como proposta oficial o Programa Nacional de Serviços Básicos de Saúde (PREV-SAÚDE). Súa versão original, de agosto de 1980, embora não sendo divulgada, chegou ao conhecimento de alguns setores, contendo entre outras as seguintes diretrizes básicas: Expansão de cobertura, por serviços básicos de saúde a toda a população, com ênfase nas medidas preventivas. reorientação do setor público, 
com a finalidade de aumentar a sua produtividade, promovendo, ao mesmo tempo, a sua incorporação ao atendimento secundário e terciário do sistema. (...) Participação comunitária considerada como um componente fundamental do desenvolvimento político da sociedade. Promoção da melhoria das condições do ambiente, compreendendo a implantação de sistemas simplificados de abastecimento de água, destino adequado dos dejetos e melhoria habitacional (....)" (MELLO, 1982)

"Este programa, na sua versão inicial e, portanto, antes de se cogitar a sua implantação, foi completamente modificado, sendo retiradas as diretrizes de reformular o modelo de saúde. Desta forma, o PREV-SAÚDE teve assim sua vida, paixão e morte". (MELLO, 1982)

Através da ação conjunta dos Ministérios da Saúde Previdência e Assistência Social, Educação, Trabalho e do Interior, surgiu em 1979, o Programa de Extensão das Ações Básicas de Saúde (PREV-SAÚDE). Esse programa foi exaustivamente discutido durante a VII Conferência Nacional de Saúde, realizada em Braślia, em março de 1980.

A proposta do PREV-SAUDE não agradou à área econômica do governo, nem às multinacionais, porque uma das suas proposições era a utilização de tecnologia apropriada, de baixo custo, isto é, uso de métodos e de materiais médico-hospitalares de eficácia comprovada e de preço ao alcançe da comunidade e do pars. Não encontrando ressonância política, o PREV-SAÚDE não pôde ser implantado. Esses programas foram fundamentados por um referencial social, que se chocava com a política oficial, motivo pelo qual, nunca foram implantados e operacionalizados nacionalmente.

Para que surgisse, no início da década de 80 , outras propostas de mudança na política de saúde, foram necessários vários determinantes, quais sejam: avanço do processo de democratização do país; aumento de insatisfação popular; ń́vel de produtividade muito aquém da capacidade instalada dos serviços públicos, principalmente o INAMPS e a crise da Previdência Sociál. entro desse contexto, foi criado o Conselho de Administração de Saúde Previdenciária (CONASP), Decreto n. 86.329, de 2 de setembro de 1981. Esse Conselho teria como função precipua assessorar o MPAS. Ele apontava todas as distorções existentes, iniciava um processo de revisão da política de assistência mє́dico-hospitalar do INAMPS e propunha a integração de todas as instituições de saúde.

O CONASP ficou entāo constiturdo de representantes de 14 entidades, a saber: Representantes dos Ministérios: Saúde, Previdência, Trabalho, Educação, Fazenda, Extraordinário para a Desburocratização, da Secretaria de Planejamento da Presidência da República, das Confederaçōes Nacional da Indústria, do Comércio, da Agricultura, dos Trabalhado- res da Indústria, do Comércio e da Agricultura e do Conselho Federal de Medicina.

Em maio de 1982, o CONASP elaborou um Plano de Reorientação da Assistência à Saúde no âmbito da Previdência Social (Portaria MPAS n. 3.062/82), cujas diretrizes foram assim resumidas:

- prioridade maior às ações primárias de saúde, com ênfase na assistência ambulatorial, cujo funcionamento adequado represente a verdadeira porta de entrada para o sistema;

- integração das instuições de saúde mantidas pelos governos federal, estadual e municipal, num mesmo sistema, regionalizado e hierarquizado, cuja amplitude pode e deve ser estimada local ou regionalmente, incluindo a população rural;

- utilização plena da capacidade de produção de serviços por essas instituiçōes, às quais devem ser asseguradas prioridade nos atendimentos à clientela;

- estabelecimento efetivo de niveis e limites orçamentários, para a a cobertura assistencial, ajustando os seus programas às condições reais da economia nacional;

- administração descentralizada dos recursos previstos;

- reconhecimentc da participação complementar da inciativa privada na prestação da assistencia;

- estabelecimento de critérios mais racionais para a prestação de serviços médicos, não só pelas instituições ou médicos privados, mas também pelos próprios estabelecimentos ou servidores públicos, com vistas à melhoria das condições de atendimento;

- simplificação concomitante dos mecanismos de pagamento de serviços prestados por terceiros, com o necessário controle pelos órgãos públicos;

- racionalização das indicações e prestações de serviços médicos de custo elevado, assim como de tratamento fora de domicnlio ou do pars, com a criação dos Centros de Referência para a prestação de tais serviços;

- implantação gradual da reforma, num prazo útil, que permita, entretanto, reajustes eventuais.

A proposta contida nesse Plano deve ser interpretada como um natural e já esperado programa de aperfeiçoamento da assistência à saúde prestada pela Previdência Social.

As Ações Integradas de Saúde (AIS) surgiram sob a forma de um Programa (PAIS) dentro desse Plano do CONASP, objetivando, principalmente, in tegrar as ações de saúde do MS, MPAS, MEC e dos governos Estaduais e Municipais. As Ações Integradas de Saúde trouxeram propostas de melhoria na qualidade assistencial e de previsibilidade orçamentária, através da implantação de um sistema racional de prestação de serviços de saúde, baseado nos 
seguintes princípios e diretrizes:

- responsabilidade do Poder Público em relação à saúde da população e ao controle do sistema de saúde;

- $\mathrm{a}$ integração interinstitucional terá como eixo o setor privado prestador de serviços;

- os programas, ações e atividades das instituições envolvidas devem ser definidos a partir do quadro de doenças mais prevalentes a nível regional e local;

- a integralidade das ações de saúde deve superar as dicotomias preventivo/curativo, individual/coletivo, ambulatorial/hospitalar;

- regionalização e hierarquização dos serviços em rede única;

- descentralização do processo de planejamento e administração;

- atendimento de qualidade com resolutividade;

- universialização e eqüidade da assistência;

- participação social nas instâncias gestoras;

- utilização plena e prioritária das instalações da rede pública, permitindo maior resolutividade dos serviços;

- respeito à dignidade dos usuários.

Para concretização dos princípios e diretrizes que norteavam as AIS, foram elaboradas estruturas funcionais e organizacionais através das seguintes Comissōes:

- Comissão Interministerial de Planejamento - CIPLAN - órgão deliberativo interministerial - MS - MPAS - MEC - MT -, fornece pautas à atuação integrada e efetiva das instituiçōes federais e realiza o acompanhamento a nível nacional das ações integradas de saúde, conta também com a participação do Conselho Nacional de Secretários de Saúde (CONASS);

- Comissões Interinstitucionais de Saúde CIS, de atuação a nível estadual;

- Comissōes Regionais Interistitucionais de Saúde-CRIS, de atuação a nível regional;

- Comissões Locais ou Municipais de Saúde - CLIS/CIMS, de atuação a nível local ou municipal.

Toda essa estrutura está envolvida no processo de planejamento, gestão, acompanhamento e avaliação das ações de saúde. A programação, a ser implantada por cada instituição participante das AIS, deve ser descentralizada, integrada e ascendente, isto é, a partir do nível local (CLIS).

As AIS foram classificadas em duas áreas de atuação, uma para as áreas gerais e outra para as áreas específicas prioritárias. As áreas compreendiam as sub-áreas:

- Assistência Médico-Hospitalar: cuidados primários; cuidados secundários; e cuidados terciários.

- Assistência Farmacêutica.
- Desenvolvimento Institucional.

As áreas específicas prioritárias abrangiam as sub-áreas:

- Promoção da Saúde da Mulher e da Criança

- Controle de Doenças Transmissíveis

- Controle de Doenças Redutíveis por Saneamento.

Apesar de todos os avanços na política de saúde, não se pode afirmar que o CONASP modificou a estrutura de funcionamento do INAMPS. Pelo contrário, aprofundou a ideologia através de uma racionalização centralizada dos instrumentos de decisão, como forma de um controle eficiente e eficaz. Manteve uma estrutura de orçamento, voltada para o custeio de serviços próprios, contratados e conveniados, pouco flexível e privilegiadora dos setores privados e, logicamente, das áreas de maior mercado consumidor. O esforço de elaboração da programação pouco tinha a ver com a montagem do orçamento, que apesar das medidas implementadas, crescia, rompendo com todas as previsões, principalmente nos serviços contratados. Os baixos reajustes e o não investimento agravou a situação de sucateamento vivida pelo setor público.

O momento brasileiro caracterizado por um processo de transição política - passagem de um longo período de regime autoritário para a implantação de uma democracia - teve o ano de 1984 como um marco histórico e decisivo, onde a população organizada exigiu as eleições diretas para Presidente da República e o fim do regime militar.

No bojo desse movimento, os problemas politicos, econômicos e sociais foram levantados e discutidos. $\mathrm{Na}$ área da saúde, os técnicos, juntamente com a população, diagnosticaram o Sistema Nacional de Saúde como descoordenado, caótico, pouco eficiente, concentrado nas regiões mais desenvolvidas e privilegiador dos interesses privados, necessitando de uma resposta rápida, factível, viável e que reformulasse tal Sistema. A meta é "Saúde como um direito de todos e um dever do Estado".

Para reverter o quadro sanitário já diagnosticado, foi necessário consolidar as AIS como uma estratégia, definida pela Resolução CIPLAN 6/84, referendada em Portaria Interministerial $\mathrm{n}$. 01/MS/MPS/MEC, de 7 de junho de 1985. A partir dessa portaria, as AIS, como estratégia ef etiva da mudanças, foi aprofundada, objetivando alcançar o Sistema Unificado, regionalizado e hierarquizado, encarregado do atendimento universal e igualitário, tendo como filosofia assistencial a integralidade e a resolutividade das ações. A Programação Orçamentação Integrada - POI - , que é o instrumento viabilizador das AIS, foi agilizada e efetivada pelas instituições componentes dessa estratégia, dando sustentação a essa Política de Saúde. Nesse processo, a participação popular é fundamental, para assegurar um acompanhamento constante em todas as fases, isto $\epsilon$, do planejamento até a avaliação, 
garantindo, dessa forma, a melhoria da qualidade dos serviços prestados.

As AIS constituem, hoje, um marco político indiscutível, atingindo uma amplitude considerável, cobrindo 2.500 municípios e $90 \%$ da população brasileira.

A articulação progressiva entre os profissionais de saúde e a população teve o seu ponto alto na VIII Conferência Nacional de Saúde, realizada em Brasflia, em março de 1986, contando com a participação de quase cinco mil pessoas, dentre as quais, mil delegados. Esse evento caracterizou-se como o mais democrático, participativo e representativo já realizado nessa área. O único setor da saúde que não compareceu à Conferência foi o da medicina privada, que alegou não concordar com a abordagem, conteúdo e organização do encontro nesse momento histórico da Saúde Brasileira.

Nessa Conferência, foram discutidos os seguintes temas: Saúde como Direito, Reformulação do Sistema Nacional de Saúde e Financiamento do Setor e os 135 grupos de trabalho (38 de delegados e 97 de participantes) apresentaram relatórios que foram consolidados em um documento tendo sido aprovado em plenária, que recomendou o Sistema Único de Saúde e a criação da Comissão Nacional da Reforma Sanitária.

A Comissão Nacional da Reforma Sanitária foi constiturda a partir da Portaria Interministerial MEC/MS/MPS n. 02/86 publicada no DOU de 22/8/86, com a finalidade de:

- Analisar as dificuldades identificadas no funcionamento da rede nacional de serviços de saúde, e sugerir opções para a nova estrutura organizacional do sistema;

- Examinar os instrumentos de articulação entre os setores de governo que atuam na área de saúde, e propor o seu aperfeiçoamento;

- Apontar mecanismos de planejamento plurianual no setor saúde, ajustando-se com precisão às necessidades dos segmentos da população a ser atendida.

A Comissão foi composta por representantes de órgãos govemamentais, Congresso Nacional e Sociedade Civil.

A partir de um movimento na enfermagem, a Presidente da Associação Brasileira de Enfermagem, Maria José Rossi integrou a Comissão Nacional da Reforma Sanitária.

A Comissão Nacional da Reforma Sanitária elaborou duas propostas essenciais para a efetivação da reformulação do sistema de saúde, a primeira, direciona-se para o componente SAUDE da nova Constituição Brasileira onde "'Saúde é um direito assegurado pelo Estado a todos os habitantes do território nacional, sem qualquer distinção", e a segunda enfocando a Nova Lei do Sistema Nacional de Saúde, em substituição à Lei 6.229/75, que define a Rede Nacional de Serviços (RENASSA).
Os Ministros de Saúde e da Previdência Social na exposição de motivos ao Presidente da República, publicada no DOU n. 136 de 21/7/87, reafirmaram que:

“A Reforma Sanitária propugna a reformulação do atual Sistema Nacional de Saúde através da institucionalização de um Sistema unificado de Saúde, e que neste processo, a consolidação e o desenvolvimento qualitativo das AIS constituem o eixo estratégico que possibilita a criação de Sistemas Unificados e Descentralizados de Saúde nos Estados, através das instâncias colegiadas das AIS (BRASIL, 1987):

- Na área federal a CIPLAN deverá criar mecanismos de articulação com a área econômica integrando organicamente, as funçōes de planejamento das diversas instituições federais.

O Conselho Nacional dos Secretários de Saúde - CONASS - teria uma função, além da participação orgânica do seu presidente, de conselho consultivo, ao qual seria submetido os assuntos mais importantes antes da deliberação.

À CIPLAN caberia coordenar a formulação do Plano Nacional de Saúde e do orçamento unificado de saúde, consolidando os orçamentos federais, estaduais e municipais e acompanhamento de suas execução.

- Na área estadual, as Comissōes Interinstitucionais de Saúde, ampliaram sua representatividade coordenando sua propria execução.

- Nas áreas micro-regionais ou municipais, as Comissões Regionais de Saúde ou Comissões Municipais de Saúde, responsáveis pela coordenação da formulação dos planos regionais ou municipais de saúde e pelo acompanhamento de suas execuções".

O SUDS (Sistema Unificado e Descentralizado de Saúde) composto pela estrutura orgânica supracitada terá a seguinte definição das atribuições dos três níveis federativos:

À UNIÃO

- Gestão, coordenação, controle e avaliação do Sistema Nacional de Saúde, em nível nacional; elaboraçāo do Plano Nacional de Saúde;

- Execução direta de serviços, de pesquisa e de cooperação técnica, de abrangência nacional; regulamentação das relaçōes entre 0 setor público e privado na prestação de serviços de saúde; normatização nacional de assistência integral à saúde, da vigilância epidemiológica, da vigilancia nutricional e alimentar, da vigilancia sanitária, do controle das condições de trabalho, do saneamento, do meio ambiente, da informação em saúde, da pesquisa e desenvolvimento tecnologico e da produção, distribuição e controle de insumos críticos; garantia da redistribuiçāo espacial dos recursos do Sistema Nacional de Saúde; implementação dos Planos nacionais de recursos Humanos, de Informação em Sa- 
úde, de Desenvolvimento Científico e Tecnológico em Saúde e de Produção e Distribuição de Insumos Críticos (equipamentos, medicamentos, imunobiologicos, sangue e hemoderivados).

AO ESTADO

- Gestão, coordenação, controle e avaliação do Sistema Estadual deSaúde; adaptação das normas e diretrizes fedrais ao Sistema Estadual de Saúde; execução direta de serviços de saúde de abrangência estadual; participação na gestão e controle de convênios com entidades públicas e privadas; elaboração e coordenação do Plano Estadual de Saúde; implementação dos Planos Estaduais de Recursos Humanos, informação em saúde, desenvolvimento cientifico e tecnológico e de produção e distribuição de insumos críticos.

AOS MUNICÍPIOS

- Gestão, coordenação, controle e avaliação do Sistema Municipal de Saúde; execução direta dos serviços de saúde de abrangência municipal, especialmente os de atenção básica, de vigilância sanitária, de vigilancia epidemiológica, de saúde ocupacional e de controle de endemias; participação na gestão e controle de convênios com entidades públicas e privadas; elaboração e coordenação do Plano Municipal de Saúde; implementação dos Planos Municpais de Recursos Humanos, informação em saúde e de distribuição de insumos críticos.

Dessa forma, o Ministério da Saúde será o órgão técnico-normativo das açōes de saúde e da proposição da política nacional de saúde. Permanecerão subordinados ao Ministério da Saúde aquelas instituiçōes altamente especializadas, de referência na cional e voltadas à pesquisa.

O INAMPS sofrerá uma redução em sua estrutura, de maneira a adaptá-lo às funçōes especificas de planejamento, orçamentação e acompanhamento. 0 processo de programação-orçamentação integrada será aperfeiçoado no sentido de conter o conjunto de recursos das instituições, de se constituir no instrumento básico da gestão colegiąda, de ser um elemento de compatibilização entre necessidades expressas epidemiologicamente e os recursos disponíveis para satisfaze-las e, finalmente, ter como seu objeto programático o distrito sanitário para, a partir dar, consolidar-se em planos municipais, estaduais e nacional.

O Distrito Sanitário, que é a unidade básica do sistema Nacional de Saúde, não pode se limitar a uma única planta física, mas abranger o conjunto dos recursos humanos e instituiçōes existentes em uma localidade com um sistema de referência e contra-referência eficiente e eficaz. Deve configurar-se em um complexo organico de serviços sócio-sanitários cu ja delimitação geográfica será definida por cada Estado, considerando a realidade local a partir de critérios previamente estabelecidos.

A Reforma Sanitária vem sendo efetivada em vários níveis: Na Assembléia Constituinte, no relatório da Subcomissão de Saúde, Seguridade e Meio Ambiente, que assimilou os dois documentos da Comissão Nacional da Reforma Sanitária; no Governo Federal, através do Decreto n. 94.657, de 20 de julho de 1987, assinado pelo Presidente da República - José Sarney - que dispõe sobre a criação de Sistemas Unificados e Descentralizados de Saúde (SUDS) e nos governos Estaduais, a partir de Convênios de Estadualização que visam constituir o Sistema Unificado e Descentralizado de Saúde, onde as instituiçōes signatrinas (MPAS/INAMPS, MTB, MS, MEC, SES) assumem os princípios e diretrizes desse processo.

Até o presente momento (julho/87), já assinaram o Convênio de Estadualização: Rio Grande do Norte, Pernambuco, Alagoas, Sergipe, Bahia, São Paulo, Paraná, Rio Grande do Sul, Rondônia, Mato Grosso, Goiás e Brasılia.

A nova configuração da rede de serviços, unificada e descentralizada, gerida por um gestor único (Secretário Estadual e/ou Municipal de Saúde), permitirá uma reordenação dos níveis de complexidade de atendimento, maior resolutividade, integralidade das açōes e continuidade no cuidado de saúde.

A Reforma Sanitária é, portanto, o movimento de construção do novo Sistema Nacional de Saúde, a partir das principais conclusōes e recomendaçōes da 8. Conferência Nacional de Saúde, isto pressupōe que:

- A saúde seja entendida como um processo resultante das condiçōes de vida e a atenção à saúde não se restrin ja à assistência médica, mas a todas as açð̃es de promoção, proteção e recuperação.

- A saúde seja um direito de todos e um dever do Estado, assegurados constitucionalmente, daf decorrendo a natureza social das açōes e serviços de saúde, subordinadas ao interesse público.

- O setor saúde seja reorganizado e redimensionado de forma a permitir o acesso universal e igualitário de toda a população a todas as açōes e serviços necessários, dentro do conhecimento e da tecnologia disponível.

A Reforma Sanitária está iniciada e deve significar um caminho irreversivel para a promoçāo da saúde no âmbito da sociedade brasileira.

\section{METODOLOGIA}

As autoras optaram por questionar enfermeiros da rede do INAMPS, das cinco macro-regiōes do país: Norte, Nordeste, Centro-Oeste, Sul e Sudeste. Para tanto, determinaram que os Estados seriam: 
Pará, Maranhão, Alagoas, Ceará, Goiás, Brasılia, Rio de Janeiro, São Paulo, Paraná, Santa Catarina.

$O$ instrumento se compõe de cinco questões abertas sobre Reforma Sanitária.

Cada Estado escolhido pelas autoras, recebeu cinco questionários, totalizando cinqüenta questionários distriburdos.

Cabe esclarecer que as regiões Norte, Nordeste e Centro-Oeste responderam todos os questionários, já a Região Sudeste só enviou sete instrumentos preenchidos (Rio de Janeiro: 5 e São Paulo: 2) e a Região Sul não os devolveu em tempo hábil.

A computação dos dados obtidos teve como base as respostas que se apresentaram com maior freqüência e a tabulação foi realizada utilizando-se o método de five-cross.

Os enfermeiros responderam trinta e sete questionários, totalizando cento e oitenta e cinco questōes em aberto, originando cinco tabelas.

$O$ instrumento respondido pelos enfermeiros possibilitou que se observasse os seguintes aspectos relacionados à Reforma Sanitária:

- conceituação;

- expectativas quanto à implantação;

- participação do enfermeiro;

- entendimento do processo em função da população;

- significado da Reforma Sanitária frente ao compromisso social da Enfermagem.

A pesquisa constatou que os respondentes possuem informações sobre a Reforma Sanitária, no entanto, com relação à conceituação, verifica-se que a maioria descreve superficialmente a questão. Por vezes, a conceituam erroneamente e um deles nem ao menos conseguiu conceituá-la.

No que se refere às expectativas referentes à Implantação da Reforma Sanitária, 43,24\% acreditam na prestação de assistência qualificada e universal; $10,81 \%$ esperam que se ef etive a teoria proposta pelas autoridades; $10,81 \%$ acreditam na democratização do poder decisório, 8,10\% preocupam-se com a isonomia salarial. Houve opiniões isoladas relacionadas com a duplicidade de empregos e uma que não acredita na proposta.

Quanto à participação do enfermeiro na Reforma Sanitária, 37,83\% afirmam que deve ser desde o planejamento até a execução, $21,62 \%$ esperam que os enfermeiros absorvam a filosofia da Reforma com poder de decisão e ainda $21,62 \%$ acredita que deva ser ativa, coerente, consciente, decisiva quanto à população e à classe.

O entendimento da Reforma Sanitária em função da população é vista por $27,02 \%$ dos enfermeiros como a participação efetiva da comunidade na implementação e controle do processo, $21,62 \%$ como universalização no atendimento, $18,91 \%$ como atendimento das reais necessidades de saúde da população e $16,21 \%$ como democratização do serviços de saúde.
Em relação ao compromisso social da enfermagem e a Reforma Sanitária $32,43 \%$ dos enfermeiros afirma ser um compromisso direto com a saúde da população (preservação e manutenção), 21 ,62\% acredita que é o momento de assumir o papel assistencial-político diante da população; $10,81 \%$ pensa que é a oportunidade de participar da transformação social do país. Outras oponiōes foram sobre a força de trabalho, a democratização das ações de enfermagem e houve até duas que não souberam avaliar qual o compromisso social do enfermeiro.

\section{CONCLUSÃO}

No Brasil a enfermagem antes de ser estruturada como profissão teve o seu perfil ligado a duas baianas no século XVIII, Francisca Lande e Ana Justina Neri. Esta última, reconhecida como figura historica nacional, destacou-se por seus serviços na guerra que a Tríplice Aliança (Brasil, Argentina e Uruguai) desenvolveu a serviço do imperialismo britânico contra o Paraguai.

Quanto ao ensino de enfermagem, a primeira escola de formação de enfermeiros foi fundada em 1890, "Escola de Enfermagem Alfredo Pinto", dirigida por médicos, que formava pessoal para atuar na área de psiquiatria. A Escola de Enfermagem Ana Neri, fundada em 1922, e reconhecida como a primeira escola de formação de enfermeiros, reproduz o modelo nightingaliano e surge voltada para a saúde pública, com a finalidade de atender a política de saúde necessária ao estado brasileiro agrário-exportador, expondo os seus objetivos e seu papel social.

Na década de 40, com o desenvolvimento do capitalismo e das indústrias, surge a classe operária, sendo criado, então, o sistema previdenciário com a assistência médica voltada para atender curativamente, de modo a assegurar a produtividade no setor industrial e os interesses capitalistas do setor saúde. É nesse contexto que a enfermagem encontra espaço para o seu desenvolvimento. Com o declínio dos serviços de saúde pública e o avanço da assistência hospitalar, a enfermagem, que era eminentemente preventiva, passa agora a ocupar a rede hospitalar majoritariamente privada, empresarial e lucrativa, atendendo aos interesses capitalistas.

$O$ ensino de enfermagem foi consolidado como matéria de Lei em 1949, procurando atender ao enfoque da época, isto é, o enfoque assistencial curativo, com destaque para as ciências físicas e biologicas e para as disciplinas profissionalizantes, sem ênfase no ensino das ciências sociais.

$\mathrm{Na}$ década de 50, a saúde pública perde cada vez mais sua importância, cedendo lugar à assistência individualizada e curativa, influenciada pela tecnologia das indústrias produtoras de equipamento farmacêuticos. Expande-se $o$ atendimento hospitalar privado que toma caráter de empresa médica. A divisão do trabalho na enfermagem é marcante e as- 
sume as características de divisão social de trabalho típico do mercado capitalista de produção, onde o trabalho é parcelado e o trabalhador de enfermagem não tem controle sobre o produto final do seu trabalho que é a assistência de enfermagem. $\mathrm{O}$ enfermeiro se distancia cada vez mais do paciente, ocupando cargos de chefia, gerenciando as ações de enfermagem e acirrando os conflitos entre enfermeiros e os demais trabalhadores de enfermagem.

A ideologia de enfermagem desde sua origem e em particular a de Ana Neri, para os brasileiros, significa abnegação, obediência, dedicação; traduzindo, desta forma, o perfil do enfermeiro, que sob esta ótica seria um profissional obediente, socialmente acrítico, porém apto a socorrer as vítmas da sociedade.

Há em todo o Brasil, no final da década de 50, 39 escolas de enfermagem e 67 cursos de auxiliar de enfermagem. Se observa que $66 \%$ dos enfermeiros, atuavam na rede de saúde pública nos anos 40 , e 9,5\% em hospitais. Em 1950, o quadro se inverte: $49,4 \%$ dos enfermeiros trabalham em hospitais e $17,2 \%$ no campo da saúde pública.

Em 1967, com a unificação dos institutos num só organismo previdenciário - INPS, a orientação nacional de saúde aprofundou o privilegiamento da prática médico-curativa, individual, especializada, em detrimento das medidas de saúde pública de caráter preventivo e de interesse da coletividade. A medicina e a enfermagem passam a consumir medicamentos e equipamentos industriais, favorecendo o desenvolvimento das empresas multinacionais e o comércio da saúde, acriticamente.

No fim da década de 60, o enfermeiro começou a especializar-se sobretudo na área curativa e administrativa, havendo um aumento do número de escolas de enfermagem na década de 70. A partir de 1979, no Congresso Brasileiro de Enfermagem, realizado no Ceará, a enfermagem começa a questionar, indagar, refletir e criticar a prática profissional no nosso país. Até então, a enfermagem desempenhava passivamente o seu papel de executora das políticas de saúde vigentes, sendo tradicionalmente caracterizada por ser um dos primeiros grupos profissionais a aderir inquestionavelmente às determinaçōes oficiais nessa área.

Desde então, tem sido denunciado nos Congressos de Enfermagem a exclusão da enfermagem, em especial do enfermeiro, dos programas oficiais de saúde, tais como o PREV-SAUDE e o CONASP.

Na VIII Conferência Nacional de Saúde (1986), a participação dos enfermeiros foi tómida e desarticulada. Mais uma vez, a categoria não deixou claro a sua inserção no processo da Reforma Sanitária. $O$ documento 'DIREITO À SAÚDE E DIREITO A ASSISTÊNCIA DE ENFERMAGEM"' elaborado pelo COFEn/ABEn, que foi apresentado na Conferência como contribuição destas entidades ao debate, relata superficialmente os temas oficiais e não expressa a realidade da enfermagem brasileira.
Eleita em outubro de 1986, a atual diretoria da ABEn realizou uma oficina de trabalho para discutir a Assistência de Enfermagem rumo à Reforma Sanitária, buscando, fundamentalmente, comprender e conceituar esta assistência como parte contributiva da saúde, pois o trabalho em saúde se caracteriza como um processo coletivo composto de áreas técnicas específicas como a medicina, odontologia, farmácia, enfermagem etc. $O$ documento conceitua ' Assistência de Enfermagem como um conjunto de ações de natureza diversa que se articulam e se complementam entre si na consecução da finalidade do trabalho em saúde"'. Esta assistência vem sendo realizada por todas as categorias de enfermagem, ou seja: enfermeiro, técnico, auxiliar de enfermagem, visitador sanitário e atendente. Diante dos resultados da pesquisa, causa preocupação o nível de conhecimento dos profissionais acerca da proposta da Reforma Sanitária, pois são os respondentes oriundos da principal Instituição envolvida (INAMPS).

Por outro lado, a formação desse profissional ainda encontra-se arraigada a princípios que não estão relacionados socialmente ao contexto atual e a sua inserção no mercado de trabalho também mostra-se adversa a um aprofundamento do compromisso social do enfermeiro.

Com a Reforma Sanitária, o enfermeiro amplia o seu campo de ação, podendo assumir um papel de destaque, favorecendo a ampla participação da sociedade civil na gestão desse processo, através do esclarecimento da população quanto à Reforma Sanitária, seus direitos e os meios de que ela dispõe para cobrá-los.

Portanto, faz-se necessário que os profissionais de enfermagem sejam capacitados com relação à proposta da Reforma Sanitária, participando das discussões, marcando sua presença de forma efetiva enquanto membro da equipe de saúde, engajados no atual momento político brasileiro, consciente de que a Reforma Sanitária representa um movimento importante, mesmo que não seja o único que efetivamente transformará o pars.

\section{REFERÊNCIAS BIBLIOGRÁFICAS}

1. ALMEIDA, Maria Cecilia Puntel de \& ROCHA, Juan Eduardo Yazille. $O$ saber de Erfermagem e sua dinensão prática. São Paulo, Cortez, 1986.

2. BRAGA, Souza de Carlos José \& PAULA, Sérgio Goes de. Saúde e previdência. Estudos de política social. São Paulo, CEBES, HUCITEC, 1981.

3. BRASIL, Leis, Decretos etc. Lei n.0 6.229, de $18^{1}$ de julho de 1975, Diário Oficial da República Federativa do Brasil, Brasilia, 18 de julho de 1975. Dispỏe sobre a Organização do Sistema Nacional de Saúde.

4. BRASIL, Leis, Decretos etc. Decreto n: 94.657 de 20 de julho de 1987. Diário Oficial da República Federativa do Brasil, Brasilia, (136): 11.503, de 21 de julho de 1987. Dispõe sobre a criação de Sistemas Unificados Descentralizados de Saúde nos Estados - SUDS - e dá outras providências. 
5. BRASIL, Comissão Interministerial de Planejamento. Resolução no 6/84. Dispõe sobre Ações Integradas de Saúde.

6. COMISSÃO NACIONAL DE REFORMA SANITÁRIA. Docionento I. FIOCRUZ, 1987.

7. CONFERÊNCIA INTERNACIONAL SOBRE CUIDADOS PRIMÁRIO DE SAÚDE. Alma-Ata, 6-12 set. 1978. Cuidados Primários de Saúde. Relatório. Brasília, OMS/UNICEF, 1979.

8. CONFERÊNCIA NACIONAL DE SAÚdE, 7, Brasília, 24-8 mar. 1980. Ancais... Brasília, Ministério da Saúde, 1980.

9. CONSELHO CONSULTIVO DA ADMINISTRAÇÃO DE SAÚDE PREVIDENCIÁRIA. Plano de Reorientą̧ão da assisência à saúde no âmbito da Previdência Social. Brasilia, 1982.

10. CONSIDERAÇÕES SOBRE O PROGRAMA NACIONAL DE SERVIÇOS BÁSICOS DE SAÚDE. In: SEMANA DE ESTUDOS SOBRE SAÚDE COMUNITÁRIA. Natal, 1981.

11. CORDEIRO, Hésio. A Indústria da Saúde no Brasil. 4. ed, Rio de Janeiro, Graal, 1980.

12. COSTA, Maria da Salete Bezerra. Assistência primária de Saúde e a prática da Enfermagem. João Pessoa, Universidade Federal da Paraíba, 1987.

13. GERMANO, Raimunda Medeiros. Educação e ideologia de Enfermagem no Brasil. São Paulo, Cortez, 1984.
14. INSTITUTO NACIONAL DE ASSISTÊNCIA MÉDICA DA PREVIDÊNCIA SOCIAL. Ações integradas da saúde. Resolução n? 117 de 20 de junho de 1984, CIPLAN, 1984.

15. MATOS, Adalgisa Vieira - A Enfermagem e o Sistema Nacional de Saúde. In: CONGRESSO BRASILEIRO DE ENFERMAGEM, 30 Belém, 16-22 jul. 1978. Anais. ... Belém, ABEn, 1978. p. 13. 30.

16. MELLO, Carlos Gentile de e CARRARA, Douglas. Saúde oficial e medicina popular. Rio de Janeiro, Marco Zero, 1982. p. 142.

17. ORGANIZACIÓN PANAMERICANA DE LA SALUD. Salud para todos en el año 2.000. Washingtons, 1980. p. 75.

18. SANTOS, Isabel dos \& VIEIRA, Cesar Augusto de Barros, Análise critica da prática atual da enfermagem no país. In Congresso Brasileiro de Enfermagem, 31, Fortaleza, ago. 1979. ANAIS... Brasilia, ABEn 1979. p. 85-91.

19. SILVA, Graciette Borges de. Enfermagem Profissional: análise crítica. São Paulo, Cortez, 1986.

20. TELXEIRA, Sônia Maria Fleury \& OLIVEIRA, Jayme A. de Araújo. In: Previdência Social: 60 anos de história da - Previdência no Brasil. Petrópolis Vozes, 1986.

21. VIEIRA, Evaldo. Estado e miséria social de Getúlio a Geisel, 1951-1978. São Paulo, Cortez, 1978. 